\section{Re: The Effects of Patient-Provider Communication on 3-Month Recovery From Acute Low Back Pain}

To the Editor: I read the article by Shaw et $\mathrm{al}^{1}$ with interest as a clinician and as a communication skills teacher.

Unfortunately, I found the paper somewhat difficult to follow. I am not sure of how to apply the conclusion in practice: "Despite limitations, results of this study suggest that providers recognize the need to adapt their communication style when confronting patients at risk for delayed recovery, even when high-risk patients ask few questions and make infrequent declarations of lifestyle/psychosocial concerns."

As is noted in the article, patients were probably wary of dealing with "company doctors"- "responsible for the medicolegal aspects of documenting work injuries." This may make the findings not generalizable to family practice (although still of use to occupational medicine).

Perhaps the most interesting finding is that in this setting, patient-centered communication does not seem to make much difference in outcomes at 3 months ( $\mathrm{Ta}-$ bles 1 and 3). ${ }^{1}$ For self-limiting conditions such as low back pain, this is may be self-explanatory. However, I believe patient satisfaction scores may be higher when physicians use more positive rapport-building and socializing/chit-chat.

The use of multiple comparisons with independentsample $t$ tests has been deprecated by statisticians. ${ }^{2}$ A linear mixed-model procedure could have been used. Significance testing results in this paper should be interpreted with caution.

Overall, the authors are to be commended for studying this important issue in a prospective and empirical fashion.

\section{Jawad Hashim, MD Department of Family Medicine Faculty of Medicine and Health Sciences UAE University mjhashim@hotmail.com}

\section{References}

1. Shaw WS, Pransky G, Roter DL, et al. The effects of patient-provider communication on 3-month recovery from acute low back pain. J Am Board Fam Med 2011;24:16-25.

2. Hashim MJ. Sigsearch: a new term for post hoc unplanned search for statistically significant relationships with the intent to create publishable findings. Account Res 2010;17: $270-2$.

doi: 10.3122/jabfm.2011.05.110131

Dr. Shaw declined to respond to this letter. 